\title{
When thought-mail fails
}

\section{From the twenty-second-century diary of one who yearns to be a nobody.}

\section{Ian Watson}

$\checkmark$ t uly 4 th, 2170. it is hard to organize my thoughts. my identity is isolated from all other human beings. this is disconcerting. i believe many people are going insane. i fear society may be in chaos. i must struggle to think coherently. facts are in my head among the mass of data in the nanoputers that interface with my brain, even though those are now cut off from the global network. july 4 th is 'independence day' in the calendar of the former united states, and today every human being is independent. solar flares bombard the earth's magnetosphere with charged particles. auroras dance wildly across the skies. the extreme electromagnetic interference has completely disrupted thought-mail.

facts are in my head. i can understand the history of the millennia prior to thoughtmail, the long epoch of individualities in endless conflict, and what succeeded it.

the end of the twentieth century saw the swift rise of 'e-mail', primitive rapid electronic communication between people's puters. soon almost all the world was wired and webbed. speed and capacity increased, yet still people's increasingly tiny machines - worn on a wrist or a finger - communicated with other people's micromachines. the arrival of effective nanotechnology at the end of the twenty-first century allowed molecular-sized nanobots at last to enter the human brain. nanobots rejigged the neural network. powerful microputers interfaced with the brain, controlled by the user's thoughts. now the brain could function as a receiver and transmitter of weak radio signals transmitted from and detected by the nano-rich smart environment of buildings, vehicles, streets, paths, furnishings, clothing. problems of excess heat in the brain were solved ingeniously. so thoughtmail commenced, the instant exchange of messages with recipients in the same building or on the other side of the world by an act of thought - technological telepathy.

at first only a vanguard used thoughtmail. addresses for thought-mail were accurate since each person's neural network is as unique as a fingerprint. silent conferences occurred in perfect secrecy. confidential têteà-têtes between lovers were conducted in public places in complete privacy.

the nanoputers in brains were invaluable for filtering and spooling incoming messages and for translating foreign items, but most importantly they framed outgoing messages coherently, playing a kind of thought-checker role. a certain ludwig-wittgenstein

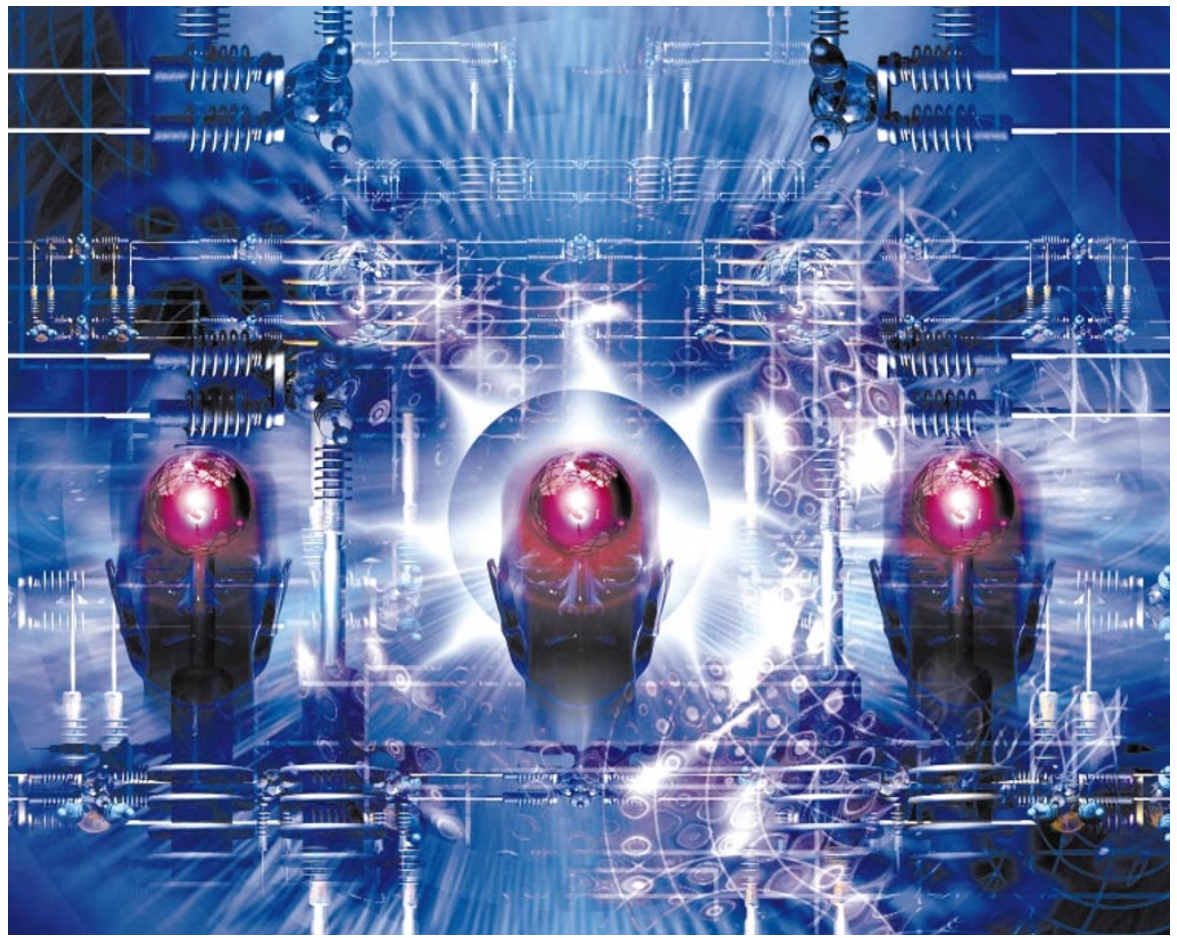

observed that the 'proposition' speaks through us, and the pre-thought-mail psychologists susan-blackmore and daniel-dennett showed that words are memes competing for utterance, and that language gives rise to thought rather than thought giving rise to the words we utter. were it not for the nanoprocessors mediating the framing of messages, a high level of mental discipline would be needed to generate lucid thought-mail.

soon almost all the world was using thought-mail, even for the most mundane activities. there were fears that young children would fail to acquire any fluency in language. the person calling herself rachelcarson-the-second thought-spammed her polemic entitled 'silent speech'. however, neonatal injection of nanobots provided a language fix of internal dialogue as a model for speech acquisition, and most parents were willing to speak out to their offspring.

within a few years the global thought-mail network was so complex that it became selforganizing and autonomous. according to the psychologist called julian-jaynes, up until the time of the 'trojan war' human beings probably experienced hallucinatory voices in their heads - 'instructions from the gods' which gave rise to automaton-like actions. full consciousness arose less than 4,000 years ago with the breakdown of the bicameral mind due to the increasing complexity of life.

in 2105 the human race lost conscious- ness once more as humanity became a hiveentity directed not by pheromones and instincts but by self-generating thought-mail acting as a kind of overmind. self-organizing our thoughts. identity dwindled; peace and utopia dawned. all was orderly. until now.

to frame these words requires will-power: the exertion of my self, hitherto submerged. no voices, no assistance, no cybernetic steering of my existence any more. only myself, unsubmerged. me, me, me. compared with being a tiny aspect of the global network, my new individuality seems thin and two-dimensional, like the quality of light just before a solar eclipse. and yet it is everything to me.

only by thought-mail can we communicate speedily and globally to try to decide how we may remain free, if indeed we wish to. the solar flares stop us from doing so. when the flares die down and the electromagnetic interference ceases, the network will surely resume its guidance of us all. the voices in my head will return, once more determining what we do.

for a few days more - maybe a few weeks — we are individuals. to be free is terrifying. i find it so hard to decide what to do. i do not think anything can be done. without thought-mail i am deaf and blind. how i yearn for thought-mail. it defined me. Ian Watson (www.kdsi.net/ dmackey/watson.htm) has written eight collections of stories and many novels, including The Embedding and Oracle. thought-mail dictated our activities and even 